\title{
Lead toxicity from glazed ceramic cookware
}

\author{
Michael Fralick MD, Aaron Thomspson MD MPH, Ophyr Mourad MD MSc
}

A 55-year-old woman presented to hospital with an acute worsening of chronic abdominal pain. Her medical history included fibromyalgia, irritable bowel syndrome, posttraumatic stress disorder and a remote cholecystectomy. She was not taking any prescription medications but was taking herbal supplements. The patient was born in El Salvador, and she had emigrated to Canada 16 years before. She was a full-time homemaker. She drank eight standard drinks of alcohol per week. She did not smoke cigarettes or take any recreational drugs. The patient's abdominal pain was diffuse, and she had nausea, nonbloody vomitus and loose stools. She reported lethargy but no recent weight loss, fevers, chills or night sweats. Results for basic laboratory investigations were normal except those for normocytic anemia (83 g/L; normal 135-180 g/L). Ultrasonography of the abdomen was normal. The patient was discharged home with instructions to followup with her family physician. Three days later, the patient presented to hospital for a second time with ongoing abdominal pain that prompted further evaluation.

The patient's vital signs were stable, and she was afebrile. She had no stigmata of chronic liver disease, but her abdomen was tender to deep palpation in all four quadrants. Examinations of her cardiac, respiratory and neurologic systems, as well as her head and neck were normal.

The patient had a hemoglobin level of $74 \mathrm{~g} / \mathrm{L}$ and a mean corpuscular volume of $90 \mathrm{fL}(80.0$ $100.0 \mathrm{fL}$ ). Serum aminotransferase levels were more than two times the upper limit of the reference range (aspartate aminotransferase $108 \mathrm{U} / \mathrm{L}$ [reference range 15-37 U/L], alanine aminotransferase $183 \mathrm{U} / \mathrm{L}$ [reference range 17-63 U/L]). Laboratory results for alkaline phosphatase (109 U/L), bilirubin $(15 \mu \mathrm{mol} / \mathrm{L})$, albumin $(43 \mathrm{~g} / \mathrm{L})$, electrolytes, serum creatinine $(59 \mu \mathrm{mol} / \mathrm{L})$ and iron studies (ferritin $100 \mu \mathrm{mol} / \mathrm{L}$, total iron-binding capacity $36 \mu \mathrm{mol} / \mathrm{L}$ ) were normal. We found no cause for the elevated aminotransferase levels (i.e., negative results for hepatitis A, B and C serology, anti- nuclear antibodies, smooth muscle actin antibodies, serum tylenol, HIV and celiac serology tests; normal hemoglobin $\mathrm{A}_{\mathrm{lc}}$ and lipid profile). Abdominal ultrasonography did not show hepatosplenomegaly. Results for esophagogastroduodenoscopy that included gastric and duodenal biopsies were normal. Both computed tomography-enterography and colonoscopy were normal. Basophilic stippling of erythrocytes was noted on blood film (Figure 1). Examination of the bone marrow showed uncommon ringed sideroblasts and basophilic stippling.

Because of the patient's nonspecific chronic abdominal pain, unexplained anemia and basophilic stippling of erythrocytes, testing for lead toxicity was ordered. The lead concentration in her blood was markedly elevated at 36 times the upper limit of normal $(3.6 \mu \mathrm{mol} / \mathrm{L}$; reference $<0.10 \mu \mathrm{mol} / \mathrm{L}$ ). A thorough exposure history did not suggest occupational exposure to lead or hobbies that would reasonably expose her to lead. The patient was taking herbal medications. Samples of these medications were sent for testing, but the results showed no significant amounts of lead.

The patient lived with her son. The lead concentration in his blood was also elevated at $0.95 \mu \mathrm{mol} / \mathrm{L}$. Both the patient and her son boiled water and cooked and consumed food and tea in ceramic pots and mugs they had purchased in Mexico (Figure 2). The patient's son reported that he used the ceramic mug less fre-

\section{KEY POINTS}

- Lead toxicity in Canada generally arises from occupational exposures, hobbies or use of Ayurvedic medications.

- Signs and symptoms of lead toxicity are nonspecific (e.g., fatigue, abdominal pain, constipation, arthralgias, headache, hypertension and anemia).

- There is no measurable concentration of lead in the blood that is considered safe.

- Identification and removal of the lead exposure is the first and most important step in the management of lead toxicity.
Competing interests: None declared.

This article has been peer reviewed.

The authors have obtained patient consent.

Correspondence to: Michael Fralick, mike. fralick@mail.utoronto.ca CMAJ 2016. DOI:10.1503 /cmaj.160182 
quently than his mother did. The pot and mug were sent for lead testing. Although the ceramic material itself did not contain lead, the glaze covering the inner and outer surfaces of the cookware and mug was $17 \%$ lead by weight.

The patient and her son were advised to stop using the contaminated cookware. Chelation therapy was considered but not used, because the patient's symptoms were resolving, and a repeat blood test showed a lead concentration below $3.5 \mu \mathrm{mol} / \mathrm{L}$. The patient's anemia, abdominal pain, arthralgias and lethargy slowly resolved over three months.

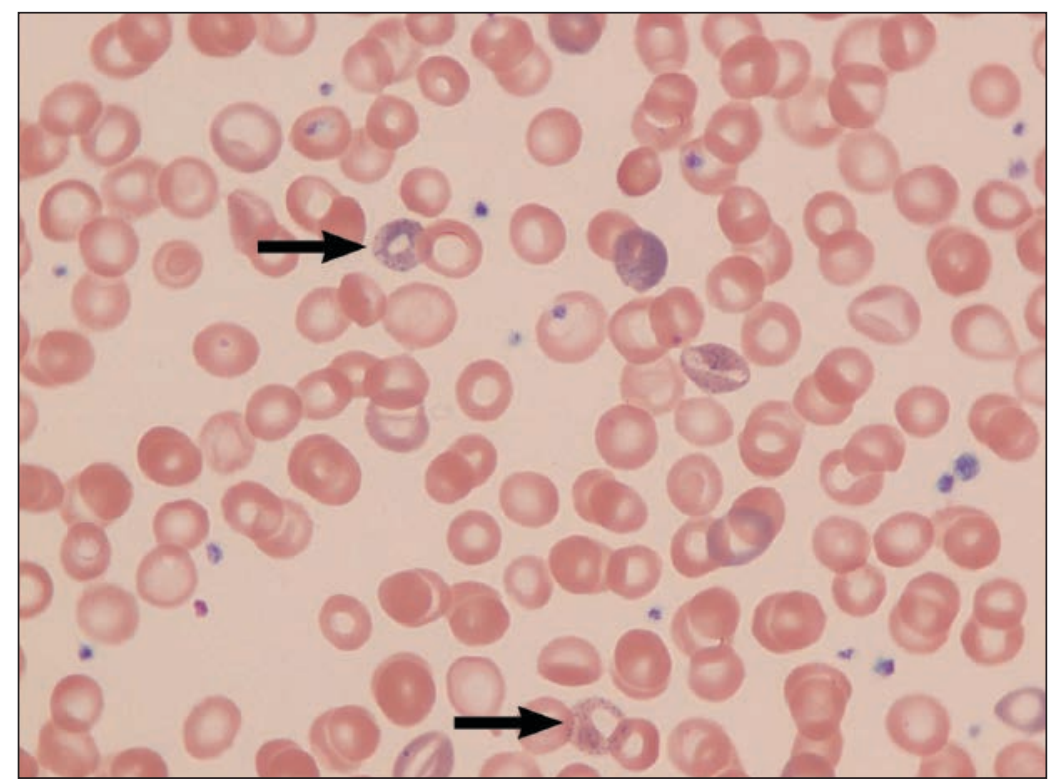

Figure 1: Blood film showing basophilic stippling of erythrocytes (arrows) in a 55-year-old woman with lead poisoning.

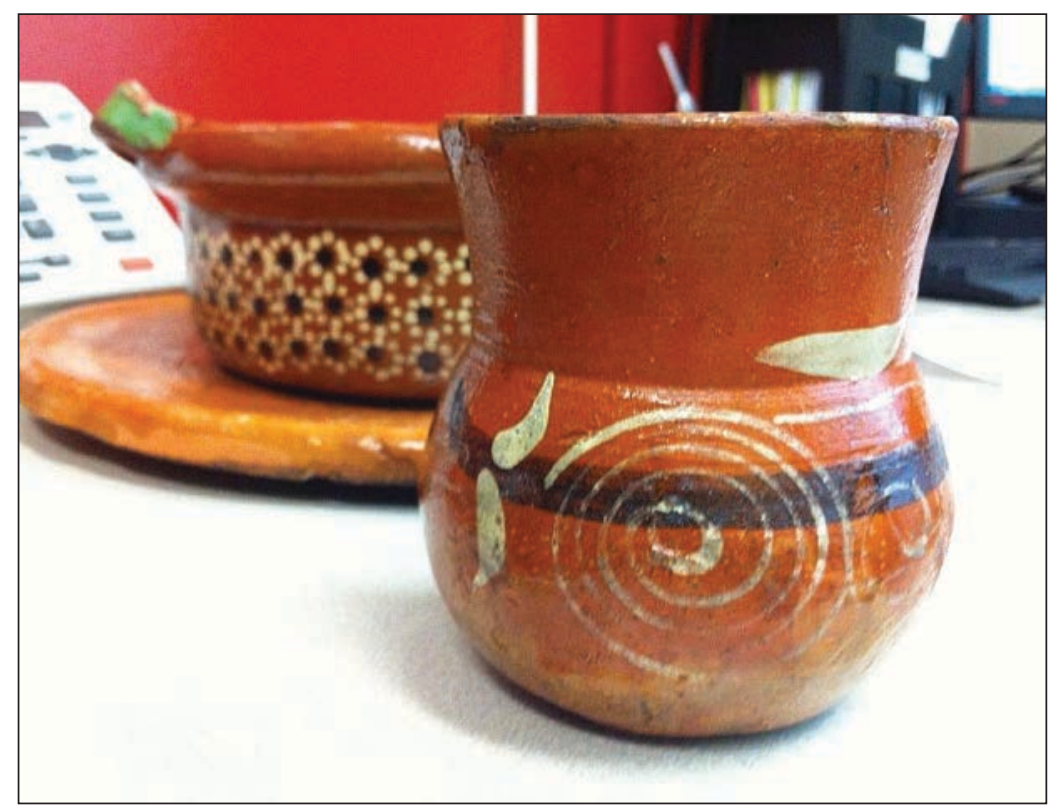

Figure 2: The tea cup and pot used by the patient. The glaze on both was $17 \%$ lead by weight.

\section{Discussion}

Lead-contaminated ceramics from Mexico, China and some European countries are wellestablished sources of clinically significant lead poisoning. ${ }^{1}$ Leaded glazes have traditionally been used on ceramic and glassware products, because they are easy to use, add colour and provide a smooth bright finish. ${ }^{2}$

The import of cookware and glassware containing lead into Canada is governed by legislation (SOR/98-176 Glazed Ceramics and Glassware Regulation); however, tourists may bring back pottery from other countries and not be aware that it contains lead. The prevalence of lead toxicity from glazed ceramic pottery in Canada is not known. Defining the prevalence of lead toxicity more generally is complicated, because the estimate depends on the outcome of interest (acute v. chronic toxicity) and the population under consideration (thresholds of toxicity differ for fetuses, children and adults). ${ }^{3}$ For the general population, the current Canadian blood lead intervention level is $0.48 \mu \mathrm{mol} / \mathrm{L}^{4}{ }^{4}$

The Statistics Canada 2007-2008 survey reported that less than $1 \%$ of the population had blood lead concentrations above the current Health Canada guidance value. ${ }^{3}$ This represents a substantial decline since 1978-1979, when survey results showed that $25 \%$ of Canadians aged six years of age or older had blood lead concentrations above $0.48 \mu \mathrm{mol} / \mathrm{L}$. ${ }^{4}$ The decline in blood lead concentrations in Canadians over the past 30 years is primarily attributable to the removal of lead from gasoline and paint. ${ }^{4}$

Lead poisoning can be either acute or chronic, although the latter is more common. ${ }^{5}$ In cases where the source is not immediately apparent, lead toxicity can be a diagnostic challenge because of the nonspecific nature of the presenting symptoms. In our case, the diagnosis was delayed, in part, because of the patient's history of irritable bowel syndrome and fibromyalgia; therefore, her symptoms were initially attributed to these diagnoses. The primary diagnostic clue was anemia with basophilic stippling.

Manifestations of acute and chronic lead toxicity depend on the severity of lead poisoning. Signs and symptoms are generally nonspecific and can include fatigue, abdominal pain, constipation, arthralgias, myalgias, headache, hypertension, renal impairment and microcytic anemia. ${ }^{5}$

There is no clearly established concentration of lead in the blood at which no harm occurs. ${ }^{6}$ Subclinical effects and risk of chronic neurologic, cardiovascular and renal outcomes may occur at blood lead concentrations as low as 
$0.48 \mu \mathrm{mol} / \mathrm{L} .{ }^{4}$ For women of reproductive age, even lower blood lead concentrations are recommended, because the developing fetus is particularly susceptible to lead toxicity. ${ }^{4}$

Overt signs and symptoms of toxicity generally do not occur until blood lead concentrations are greater than $2 \mu \mathrm{mol} / \mathrm{L}^{7}$ Anemia usually occurs at blood lead concentrations greater than $2.5 \mu \mathrm{mol} / \mathrm{L}$, and neurologic symptoms (e.g., seizure, encephalopathy, tremor) may manifest when blood lead concentrations exceed $4.5 \mu \mathrm{mol} / \mathrm{L}^{7}$

Physical examination of patients with lead poisoning is often normal. Hypertension may be observed with blood lead concentrations greater than $0.48 \mu \mathrm{mol} / \mathrm{L}$, although this finding is nonspecific. ${ }^{7}$ Postural balance may be impaired when blood lead concentrations are in the range of 1.5 to $3 \mu \mathrm{mol} / \mathrm{L}$, whereas diffuse abdominal pain may be apparent at concentrations of $2-3 \mu \mathrm{mol} / \mathrm{L} .^{7}$ Bluish pigmentation at the gum-tooth interface, known as lead lines, is uncommon and not a reliable indicator of lead poisoning. ${ }^{7}$

\section{Diagnostic evaluation}

Anemia is common and may be either microcytic or normocytic. ${ }^{5,8}$ Basophilic stippling of erythrocytes is frequently observed but is neither sensitive nor specific for lead poisoning (Box 1) ${ }^{5,8}$ Hyponatremia owing to syndrome of inappropriate antidiuretic hormone and mild to moderately elevated liver enzymes from hepatocyte toxicity may also be observed. ${ }^{5,}$ In severe cases, acute kidney injury may occur. ${ }^{5}$

Elevated blood lead concentrations are required for diagnosis. ${ }^{5}$ Lead concentrations in urine and hair are neither accurate nor reliable indicators of lead toxicity. ${ }^{9}$ Because there is no measurable blood lead concentration that does not cause harm, ${ }^{6}$ results less than $0.48 \mu \mathrm{mol} / \mathrm{L}$ do not suggest overt toxicity but do warrant taking a complete occupational and environmental exposure history to try to determine the source. ${ }^{6}$ In cases where no source is identified and the blood lead concentration exceeds $0.48 \mu \mathrm{mol} / \mathrm{L}$, referral to a physician with experience in the assessment and treatment of lead toxicity is recommended.

\section{Management of lead poisoning}

Identification of the lead source and removal of the patient from exposure is the most important step in the management of lead toxicity. ${ }^{9}$ Most substantial lead exposure for adults in Canada occurs in the workplace, but nonoccupational exposure may occur in a variety of settings (Box 2). ${ }^{6}$ Ayurvedic (traditional Indian) medi- cines are increasingly associated with lead poisoning; therefore, it is important to include questions about the use of herbal and traditional medications in the medication history. ${ }^{9}$

Among children in Canada, leaded paint is the main source of lead concentrations in blood. Leaded paint, which may be chipping or crumbling, is found in older homes (built before 1978) and can be ingested as a result of handmouth behaviours or pica. ${ }^{4}$

Once the source of the lead is identified, and the patient is no longer exposed, serial testing of the patient's blood lead concentration is effective in establishing whether lead sources have been eliminated..$^{10}$ The half-life of lead in the blood is about 30 days. Monthly monitoring is recommended for patients with blood lead concentrations greater than $1 \mu \mathrm{mol} / \mathrm{L}$ and every three to six months when concentrations are greater than $0.48 \mu \mathrm{mol} / \mathrm{L}$ but below $1 \mu \mathrm{mol} / \mathrm{L} .{ }^{6,10}$

In cases of severe toxicity, chelation therapy is effective in acutely lowering blood lead concentrations, and anecdotal evidence suggests this improves symptoms; however, controlled clinical trials are lacking. ${ }^{10}$

Expert opinion suggests that chelation therapy be considered in symptomatic patients with blood lead concentrations between 3.5 and $5 \mu \mathrm{mol} / \mathrm{L}^{10}$ and in all patients with blood lead concentrations greater than $5 \mu \mathrm{mol} / \mathrm{L} .{ }^{10}$ Chelation therapy most often involves calcium disodium versenate (CaNa2EDTA) or dimercaptosuccinic acid (succimer) ${ }^{10}$ Both agents have the potential for serious adverse effects, and patient monitoring during treatment is required. Neither

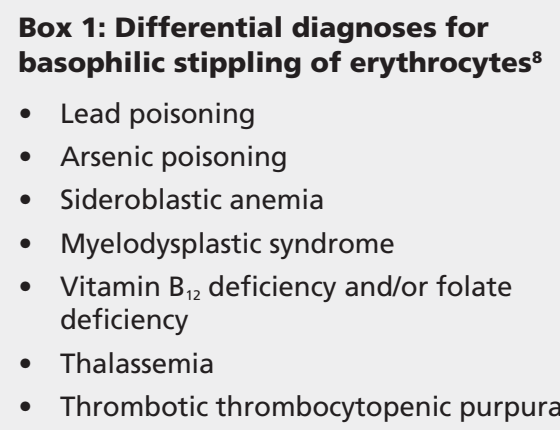

Box 2: Sources of exposure to lead in Canada ${ }^{2,4}$

- Occupational: plumbing, battery manufacturing and recycling, construction work, exposure to ammunition and soldering

- Environmental: lead paint, lead pipes, ceramic ware

- Other: Ayurvedic medications and herbal remedies, cosmetics 
drug is covered by provincial health insurance plans in Canada. A physician experienced in chelation therapy should be consulted before starting chelation therapy.

\section{References}

1. Sheets RW. Acid extraction of lead and cadmium from newly purchased ceramic and melamine dinnerware. Sci Total Environ 1999;234:233-7.

2. Consumer product safety: glazed ceramics and glassware regulations - dealer information. Ottawa: Health Canada; [modified 2015]. Available: www.hc-sc.gc.ca/cps-spc/pubs/indust/ceramics -ceramiques/index-eng.php (accessed 2016 Mar. 14).

3. Wong L, Lye EJD. Lead, mercury and cadmium levels in Canadians. Ottawa: Statistics Canada; 2008. Cat no 82-003-x. Available: www.statcan.gc.ca/pub/82-003-x/2008004/article/6500822-eng.pdf (accessed 2016 Mar. 14).

4. Final Human Health State of the Science report on lead. Ottawa: Health Canada; 2013. Available: www.hc-sc.gc.ca/ewh-semt/ pubs/contaminants/dhhssrl-rpecscepsh/index-eng.php (accessed 2015 Dec. 9)

5. Patrick L. Lead toxicity, a review of the literature. Part 1: exposure, evaluation and treatment. Altern Med Rev 2006;11: $2-22$.

6. Sanborn MD, Abelsohn A, Campbell M, et al. Identifying and managing adverse environmental health effects: 3 . Lead exposure. CMAJ 2002; 166:1287-92.

7. Abadin H, Ashizawa A, Stevens YW, et al. Toxicological profile for lead. Atlanta: Agency for Toxic Substances and Disease Registry; 2007.

8. Cheson BD, Rom WN, Webber RC. Basophilic stippling of red blood cells: a nonspecific finding of multiple etiology. Am J Ind Med 1984;5:327-34.

9. Saper RB, Phillips RS, Sehgal A, et al. Lead, mercury, and arsenic in US- and Indian-manufactured ayurvedic medicines sold via the Internet. JAMA 2008;300:915-23.
10. Kosnett MJ, Wedeen RP, Rothenberg SJ, et al. Recommendations for medical management of adult lead exposure. Environ Health Perspect 2007; 115:463-71.

Affiliations: Department of Medicine (Fralick, Thompson, Mourad), University of Toronto; Division of General Internal Medicine, Department of Medicine (Fralick, Mourad); Division of Occupational and Environmental Health (Thompson), St. Michael's Hospital, University of Toronto; Dalla Lana School of Public Health (Thompson), University of Toronto, Toronto, Ont.

Contributors: All of the authors contributed substantially to the interpretation and analysis of the data, and writing and revising the article, gave final approval of the version to be published and agreed to act as guarantors of the work.

The section Cases presents brief case reports that convey clear, practical lessons. Preference is given to common presentations of important rare conditions, and important unusual presentations of common problems. Articles start with a case presentation (500 words maximum), and a discussion of the underlying condition follows (1000 words maximum). Visual elements (e.g., tables of the differential diagnosis, clinical features or diagnostic approach) are encouraged. Consent from patients for publication of their story is a necessity. See information for authors at www.cmaj.ca. 